\title{
Earthquake stability assessment for open pit mine slopes
}

\author{
J.C.W. Toh Pells Sullivan Meynink, Australia \\ D.K.E. Green Pells Sullivan Meynink, Australia \\ G.E. Swarbrick Pells Sullivan Meynink, Australia \\ M.J. Fowler Pells Sullivan Meynink, Australia \\ B.E. Estrada Pells Sullivan Meynink, Australia
}

\begin{abstract}
Earthquake stability assessment of large open pit mine slopes brings together two areas of slope engineering that are usually quite separate. To account for the scale and nature of open pit slopes, analysis techniques widely used for small scale civil infrastructure slopes need to be adapted and then extended.

The first part of this paper presents a framework for earthquake stability assessment of open pit mine slopes that has been used in practice by the authors. The framework attempts to provide consistency across various analysis techniques, from pseudo-static analysis to dynamic numerical modelling. Guidance is given for selecting an appropriate earthquake load coefficient for pseudo-static analysis.

The second part of this paper presents two examples of dynamic numerical modelling. One example demonstrates that the earthquake response of large rock slopes is highly dependent on the interaction between the seismic hazard, the resonant behaviour of the slope and surrounding ground, the rock mass character, and the slope geometry, and it follows that understanding dynamic site response is an integral part of earthquake engineering for large rock slopes. The other example presents parts of a detailed analysis of slope stability and deformation, and compares the results to those obtained from simpler analysis methods.
\end{abstract}

\section{Introduction}

For some open pit rock slopes a high level of earthquake engineering is required, for example pit slopes in areas of high seismicity with high consequences of failure. Because pit slope design is it not a 'classic' earthquake engineering subject, there is little precedent for analysis methodologies or results. The engineering involved in assessing earthquake stability of large open pit rock slopes is somewhat different to that involved for small soil slopes, so a different approach is required. For example, the size of open pit slopes results in two effects that are not as prevalent in smaller slopes; topographical amplification effects, and scale related averaging effects. Rock slopes also have quite different dynamic characteristics to soil slopes.

Read and Stacey (2009) state that there are no recorded case histories of large scale earthquake-induced mine slope failures having disrupted mining operations, and the authors of this paper are not aware of any evidence to the contrary. This may suggest that there is little crossover between the fields of earthquake engineering and open pit mining. However the world case history database is by no means extensive.

\section{Framework}

The authors have developed a framework for earthquake stability assessment of open pit slopes that attempts to provide consistency across several different types of analysis, by accounting for topographical amplification effects, scale related averaging effects, and other important inputs. Although it is currently straightforward it can be developed or refined. 
Table 1 Summary of earthquake stability assessment framework

\begin{tabular}{|c|c|c|}
\hline Level & Analysis Type & Potential Outcomes \\
\hline \multirow[t]{2}{*}{1} & \multirow{2}{*}{$\begin{array}{l}\text { 'Pseudo-static' limit equilibrium } \\
\text { slope stability analysis, including a } \\
\text { horizontal inertial force to represent } \\
\text { earthquake load, calculated as a } \\
\text { proportion of weight. }\end{array}$} & $\begin{array}{l}\text { 1) Sufficient results obtained in most scenarios, } \\
\text { provided earthquake load appropriately } \\
\text { represented. }\end{array}$ \\
\hline & & $\begin{array}{l}\text { 2) For high risk slopes, further analysis required } \\
\text { to overcome limitations and assumptions of } \\
\text { analysis. }\end{array}$ \\
\hline \multirow[t]{2}{*}{2} & \multirow{2}{*}{$\begin{array}{l}\text { Empirical and/or quantitative } \\
\text { estimation of slope displacement } \\
\text { using one or more methods based } \\
\text { around the Newmark 'sliding block' } \\
\text { approach (if limit equilibrium Factor } \\
\text { of Safety is less than unity). }\end{array}$} & $\begin{array}{l}\text { 1) Usually adequate if material not subject to } \\
\text { strength loss upon yield, and if exact magnitude } \\
\text { of displacement is not critical. }\end{array}$ \\
\hline & & $\begin{array}{l}\text { 2) If material behaviour is contractive or highly } \\
\text { non-linear, or strength loss may occur, or } \\
\text { detailed estimations of displacements within } \\
\text { and around slope are important, further analysis } \\
\text { required. }\end{array}$ \\
\hline 3 & Dynamic numerical analysis. & $\begin{array}{l}\text { Detailed understanding of slope response } \\
\text { during earthquake. Provides feedback to } \\
\text { confirm assumptions made during lower levels } \\
\text { of analysis. }\end{array}$ \\
\hline
\end{tabular}

The framework focusses on assessing 'global' stability of pit slopes (stability of potential slip masses at multi-bench scale and larger). It should also be applicable to other large rock cuts, the main difference between civil infrastructure slopes and open pit slopes often being design life and performance requirements. The framework intends to:

- Focus on practical applicability.

- Include analysis types ranging from simple to complex, acknowledging that the seismic setting and/or risk profile of most open pit mines would not require a rigorous assessment.

- Adapt analysis techniques from established approaches to earthquake slope stability assessment, and extend them so they are appropriate for large open pit rock slopes.

- Obtain coherent and consistent results between analysis techniques, including feedback loops to build on experience gained within and between projects.

The framework is summarised in Table 1 and features three levels of analysis. The results of each level of analysis provide more detailed quantification of seismic performance compared to the previous level(s), but the complexity of inputs and analysis also increase. Therefore it is envisaged that a typical assessment would start at the first level and only move on to subsequent levels if results indicate potential issues or unacceptable risk. Further details on the three levels are provided in the following three sections.

\section{3 'Pseudo-static' limit equilibrium analysis}

\subsection{Description}

Limit equilibrium stability analysis, including application of a horizontal inertial force to represent earthquake loading, gives a Factor of Safety against slope instability and therefore an indication of whether a slope might yield during an earthquake. This type of analysis is easily accessible and so in the framework, the authors use limit equilibrium analysis as an initial screening. More advanced analyses are only undertaken if the results do not provide sufficient confidence of earthquake stability. 


\subsection{Assumptions and limitations}

Some key limitations of limit equilibrium analysis, in particular respect to earthquake stability of large open pit rock slopes, are set out below.

1. Potential slip masses are assumed to be rigid and slide along discrete surfaces, with failure occurring at the same time along the entire surface.

2. Deformations or yielding not occurring along these defined surfaces are not addressed.

3. Progressive failure along a slip surface, including strength loss, cannot be modelled.

4. The analysis represents only one instant in time, typically the instant of maximum acceleration.

5. Model parameters (e.g. material strengths, groundwater pressures) are constant. This paper does not address the important issue of dynamic rock mass response; however it is noted that the potentials for strength loss and dynamic pore pressures are important considerations. If materials are contractive and may experience strength loss on shearing, and/or may experience increased pore pressures due to dynamic loading, these effects may need to be estimated empirically.

6. Earthquake loading is typically represented by a single, constant coefficient which is proportional to weight. This coefficient is related to the peak ground acceleration (PGA), but is not equal to it. An often overlooked factor is that loading from the same earthquake differs depending on the slope geometry and the size and location of the potential slip surfaces being investigated. This requires multiple analyses even for a single slope subjected to a single earthquake.

Limitations 1 to 3 cannot be easily overcome within the limit equilibrium approach. Limitation 4 is inconsequential if the slope does not yield, and it can be addressed by extension of the limit equilibrium analysis to include displacement assessment based on earthquake duration, see below. Limitations 5 and 6 can usually be adequately addressed for screening analysis purposes, limitation 6 is addressed below.

\subsection{Selection of earthquake load coefficient}

\subsubsection{Background}

The accelerations experienced by potential failure masses within a pit slope during an earthquake are related to, but differ from, the 'flat ground' peak ground acceleration (PGA) that is typically provided by a seismic hazard assessment. The 'pseudo static' earthquake loading coefficient (often denoted $k_{h}$ ) is often taken as somewhere between 50 and $100 \%$ of the PGA.

Assuming that $k_{h}$ equals $100 \%$ of the PGA is often very conservative and often gives unacceptable stability (Factor of Safety less than unity) in all but the most seismically benign environments, especially given the relatively low static stability of pit slopes - not much earthquake loading is required to decrease Factor of Safety to below unity. Therefore, it is often important to be able to justify that $k_{h}$ is less than $100 \%$ of PGA.

General guidance is given below in selecting a value of $k_{h}$ based on 'flat ground' PGA, which goes some way to achieving compatibility between analysis types. However as will be shown later in the paper, the earthquake loading experienced by a slope is actually highly dependent on the spectral acceleration characteristics of the earthquake, of which the PGA is only one component.

\subsubsection{Topographical effects}

Topographical effects are reasonably well understood for natural topography, but possibly not as well understood in the context of earthquake engineering for large rock slopes. For open pit mine slopes excavated into a flat ground surface, these effects can lead to ground motions at the crest of a slope being more (or less) intense than the 'flat ground' motion. The amount of amplification (or reduction) depends on the dynamic characteristics of the pit slope (rock mass stiffness, slope geometry, natural periods of resonance), compared to the spectral characteristics of the earthquake motion. 


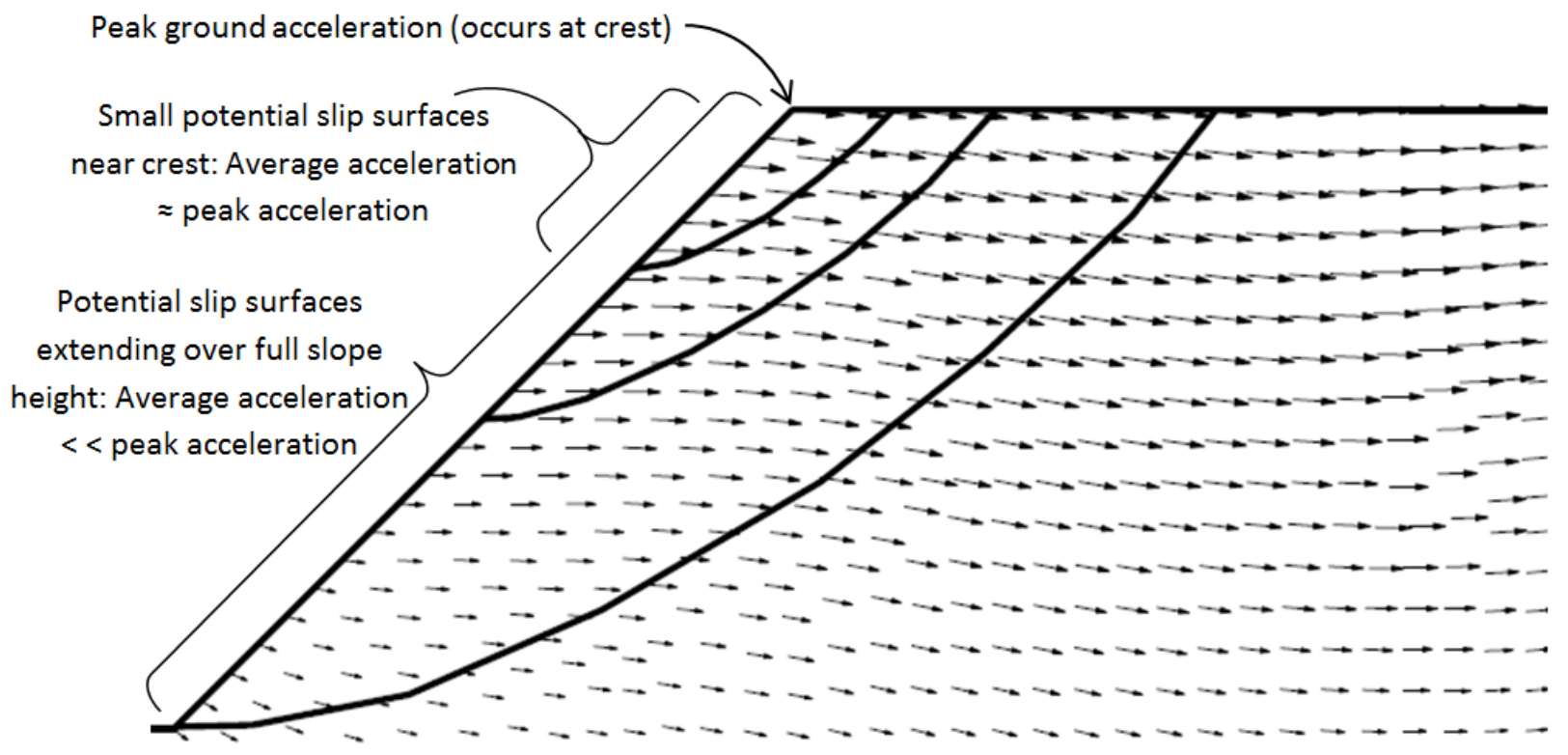

Figure 1 Example of modelled accelerations, at instant of maximum acceleration, varying throughout a $300 \mathrm{~m}$ high slope

Most studies reported in the literature, e.g. by Ashford et al. (1997), and by Bouchon (1973), generally report that the amplification or reduction is highly sensitive to the combination of these characteristics. Toh (2010) presents a more detailed literature review, as well as some generic analysis that shows that the PGA at the pit crest could be amplified by up to $17 \%$ from the 'flat ground' PGA, with greater amplifications (over $35 \%$ ) of spectral accelerations at other periods greater than zero seconds (PGA being the spectral acceleration at a period of zero seconds).

Based on this somewhat limited information, the authors usually adopt a topographical amplification of $20 \%$ for initial screening analyses of pit slopes excavated into flat ground (being towards the upper end of expected amplifications for such slopes), and confirm by dynamic numerical modelling if required. For excavations into existing natural topography, e.g. into mountain sides, topographical amplification due to the natural topography will have to be accounted for as well.

\subsubsection{Scale related averaging effects (effect of slip surface size and location within slope)}

Scale related averaging effects occur in large slopes where the maximum ground acceleration acting at any one instant during an earthquake occurs over a small area, whereas at the same time, the remainder of the slope may be subject to much lower accelerations, or accelerations in the other direction. This is because the slope is often large in comparison to the seismic wavelength, and the effect means that the PGA is not always an appropriate representation of the average accelerations experienced by large potential slip masses. Note this is similar to part of the well known approach to the seismic response of earth dams by Makdisi and Seed (1978) which involves calculating the maximum average acceleration of a slip mass based on a factoring down the acceleration at the crest of the dam.

This effect means that the loading for a given earthquake varies depending on the size and location of a potential slip mass. The averaging effect is greater for larger potential failure masses; Toh (2010) presents a generic example of this. Rudimentary estimations of scale averaging effects can also be made by comparing the wavelengths of the strongest earthquake motions with the height and shear wave velocity of the pit slope. Figure 1 shows an example of accelerations within a $300 \mathrm{~m}$ high slope, where accelerations within a slip surface extending from crest to $1 / 4$ slope depth is relatively constant, but average acceleration within a slip surface over the entire slope height is much lower than the maximum acceleration (at the crest). 


\subsubsection{Summary of generic recommendations}

Based on the above and previous analysis experience the authors usually adopt the following for estimating the earthquake loading coefficient $k_{h}$ for initial screening limit equilibrium analyses.

$$
k_{h}=\text { 'Flat ground' PGA } \times \text { Amplification factor } \times \text { Scale averaging factor }
$$

Where:

$$
\begin{aligned}
& \text { 'Flat ground' PGA = Peak ground acceleration at surface of flat ground bedrock site. } \\
& \text { Amplification factor = Ratio of PGA at slope crest to 'flat ground' PGA, up to } 1.2 \text { for rock slopes }
\end{aligned}
$$

Following this, $k_{h}$ would be less than the 'flat ground' PGA for potential slip surfaces extending the entire height of the slope. Numerical analysis would allow these estimates to be refined for a given pit slope, and is recommended for any critical applications. Also refer to the parametric study presented in Section 6.

\section{Displacement assessment based on limit equilibrium analysis}

Methods of assessing displacement based on limit equilibrium analysis can be a useful way to investigate displacement patterns of different slip surfaces. Displacements will only be calculated if the pseudo-static Factor of Safety is less than unity. The authors have used the following approaches to empirically assessing displacements, all of which are based on Newmark's 'sliding block' method:

1. Purely empirical methods, for example the charts by Ambraseys and Menu (1988).

2. Manual 'sliding block' calculations based on calculating the yield acceleration and then double-integrating the portions of an earthquake acceleration time history that exceed the yield acceleration. This is a slight improvement on (1) above because it can account for the duration of earthquake excitation and other earthquake characteristics, but involves more calculation effort.

3. Automated 'sliding block' calculations based on stresses calculated in elastic dynamic numerical analysis with earthquake acceleration time histories, e.g. in the software package Quake/W (Geo-Slope, 2007). This approach accounts for dynamic stresses, the flexibility of the slope, the variation of acceleration within a slip mass, and topographical amplification effects.

The first three limitations for limit equilibrium analysis listed above are also limitations for all of these approaches. Because of this the authors have found that displacement analyses based on limit equilibrium analyses are usually more useful in providing a link between limit equilibrium analysis and numerical dynamic modelling, rather than useful as a stand-alone analysis.

\section{$5 \quad$ Dynamic numerical analysis}

\subsection{Description}

Dynamic numerical analysis can overcome the technical limitations of limit equilibrium analysis but are computationally expensive. The authors have used the software packages Abaqus (Simulia, 2012), FLAC 
(Itasca, 2007), and Quake/W (Geo-Slope, 2007), to undertake dynamic numerical analysis. Compared to limit equilibrium and static numerical modelling, significantly more inputs are required to undertake dynamic numerical modelling including earthquake ground motion characteristics and a suite of dynamic material properties. Many of the inputs are not well understood for large hard rock slopes.

Because the results of dynamic analysis can be very sensitive to the interaction between inputs, great care is required in selecting inputs. Often a range of values for several key parameters need to be considered, especially as usually neither the parameters nor the nature of the interaction are well known. A good example of this is selection of material stiffness parameters; underestimating stiffness is often unconservative for dynamic analysis, because it results in a more flexible slope being analysed which often attracts less dynamic load. This interaction is further demonstrated in the parametric analysis example.

\subsection{Output and feedback to previous stages}

Table 2 Summary of some types of dynamic numerical analysis

\begin{tabular}{|c|c|c|c|}
\hline $\begin{array}{l}\text { Analysis } \\
\text { Type }\end{array}$ & Modal (Frequency Domain) & Elastic Time Domain & Elasto-Plastic Time Domain \\
\hline \multirow[t]{4}{*}{$\begin{array}{l}\text { Critical input } \\
\text { parameters. }\end{array}$} & Material stiffness. & $\begin{array}{l}\text { Material stiffness and } \\
\text { damping. }\end{array}$ & $\begin{array}{l}\text { Material stiffness and } \\
\text { damping. }\end{array}$ \\
\hline & & Earthquake time histories. & Earthquake time histories \\
\hline & & & $\begin{array}{l}\text { Material yield criteria and } \\
\text { post yield behaviour. }\end{array}$ \\
\hline & & & $\begin{array}{l}\text { Dynamic pore pressures if } \\
\text { applicable. }\end{array}$ \\
\hline Key outputs. & $\begin{array}{l}\text { Modes (resonant periods) } \\
\text { of pit slope, mode shapes } \\
\text { give an indication of likely } \\
\text { dynamic mechanisms and } \\
\text { pit slope movement. }\end{array}$ & $\begin{array}{l}\text { Modelling of dynamic } \\
\text { stresses and strains } \\
\text { throughout slope, over the } \\
\text { duration of an earthquake, } \\
\text { predicts locations of pit } \\
\text { slope deformation, according } \\
\text { to areas of high shear strain. }\end{array}$ & $\begin{array}{l}\text { Development of dynamic } \\
\text { yield mechanisms with time } \\
\text { and space, therefore } \\
\text { expected magnitude of pit } \\
\text { slope deformation from } \\
\text { yielding that both } \\
\text { continuous and } \\
\text { discontinuous, both in time } \\
\text { and space. }\end{array}$ \\
\hline $\begin{array}{l}\text { Key feedback } \\
\text { to previous } \\
\text { levels in } \\
\text { framework. }\end{array}$ & $\begin{array}{l}\text { Confirmation of appropriate } \\
\text { period range over which } \\
\text { earthquake time histories } \\
\text { should be scaled to match } \\
\text { design spectrum. }\end{array}$ & $\begin{array}{l}\text { Understanding of average } \\
\text { acceleration within potential } \\
\text { slip masses and of } \\
\text { acceleration at slope crest } \\
\text { compared to 'flat ground' } \\
\text { PGA, indicating appropriate } \\
\text { acceleration coefficient for } \\
\text { pseudo-static analysis. }\end{array}$ & $\begin{array}{l}\text { Refined understanding of } \\
\text { slope deformations } \\
\text { compared to simpler } \\
\text { methods. }\end{array}$ \\
\hline
\end{tabular}

Various types of dynamic numerical analysis can be undertaken, for example analysis in either the frequency domain (modal analysis) or in the time domain (elastic or elasto-plastic analysis of the slope in response to earthquake acceleration time histories). Some types of analyses that the authors have undertaken are summarised in Table 2, including the outputs they provide in regards to potential pit slope instability mechanisms. Also summarised is the feedback that each type provides to more basic types of analysis; the authors consider this feedback to be an important part of the framework. 


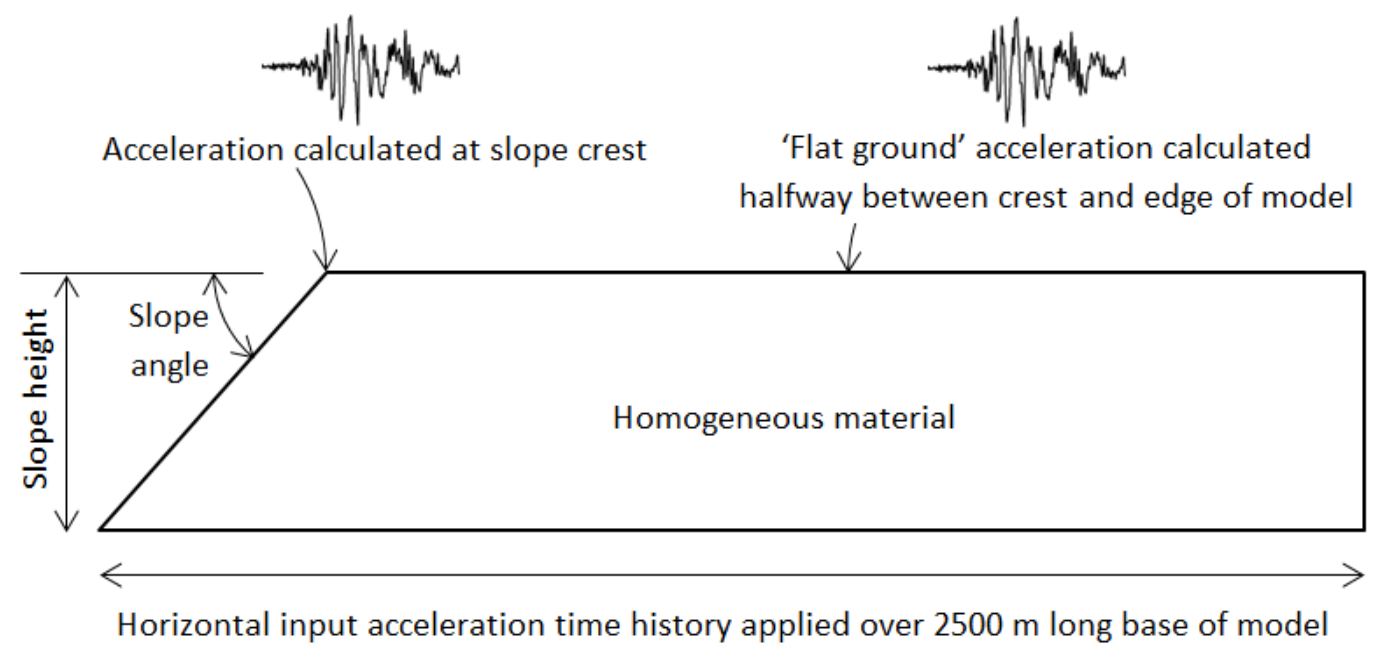

Figure 2 Model for parametric study

\section{$6 \quad$ Example of parametric study}

\subsection{Preamble}

To demonstrate some of the ideas discussed above, a parametric study undertaken using dynamic numerical modelling is presented. In particular the results presented demonstrate how the slope characteristics interact with the earthquake motion characteristics.

A simple model comprising one homogeneous elastic material was analysed (Figure 2), with the absorbing model boundaries set back far enough from the area of interest to not significantly affect results. The mesh comprised quadrilateral elements with a maximum side length of $10 \mathrm{~m}$. A 'base case' was adopted, and then three parameters were varied one at a time, as below:

- Slope height, 'base case' 300 m, with heights of 100, 200, 400, and 500 m investigated.

- Slope angle, 'base case' $45^{\circ}$, with angles of $35,40,50$, and $55^{\circ}$ investigated.

- Small strain elastic rock mass modulus 'base case' 2,500 MPa, with moduli of 1,500, 2,000, 3,000, $3,500,10,000$, and 15,000 MPa investigated.

\subsection{Pit slope modes (resonant periods)}

The first mode of the pit slope was calculated for each analysis case. This can be calculated manually, but for this example the calculations were undertaken using the Abaqus software (Simulia, 2012). The first mode for this purpose is defined as the longest natural period of the pit slope that involves resonance of the slope in a primarily horizontal direction. Figure 3 shows an example of the first mode of a pit slope.

Other modes are of shorter period, and involve excitation of different parts of the slope. Mode shapes are affected by the geological profile, but this cannot be observed in this homogeneous example analysis. Three dimensional effects may also be important for pit slopes, but are not considered in this paper.

Figure 4 plots the first mode periods calculated for the various parametric analyses overlaid on an example design response spectrum. In general, the effects of the three investigated parameters on the pit slope first mode are:

- Rock mass modulus - a stiffer slope has a shorter natural period, of the three parameters investigated rock mass modulus has by far the greatest effect on the pit slope natural period.

- Slope height - a higher slope is more 'flexible' and therefore higher slopes have longer natural periods, although in this example the effect is only apparent for slopes higher than $300 \mathrm{~m}$. 
- Slope angle - a steeper slope has a slightly longer natural period, but the effect is not strong.

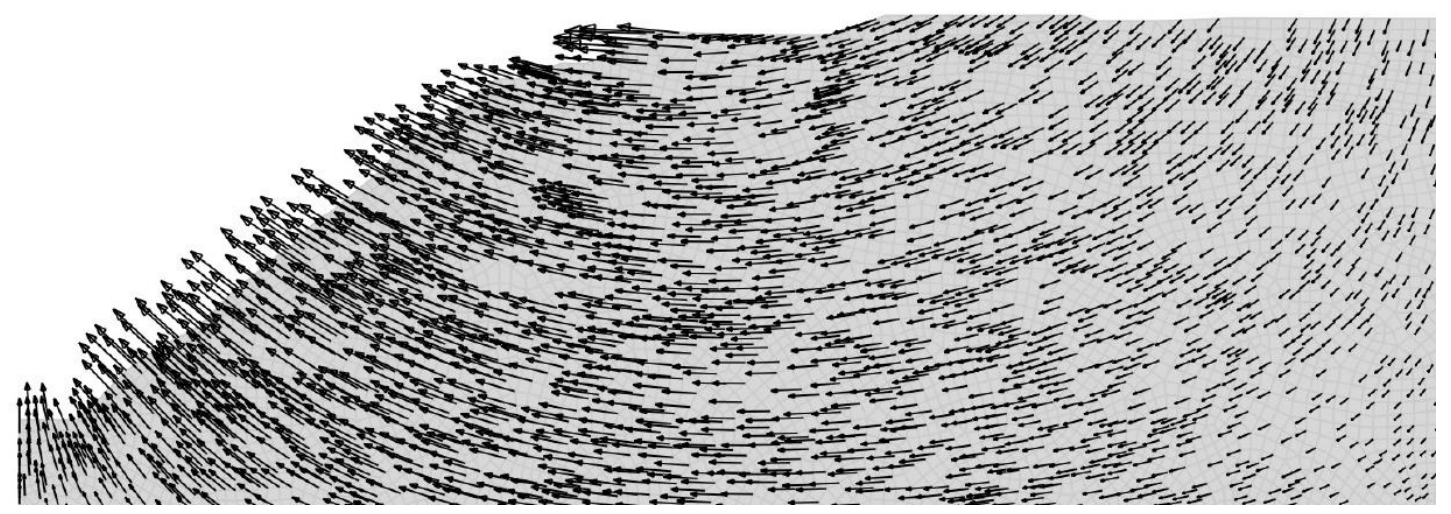

Figure 3 Example pit slope first mode, mode shape includes resonance in the direction of the arrows, and the opposite direction of the arrows

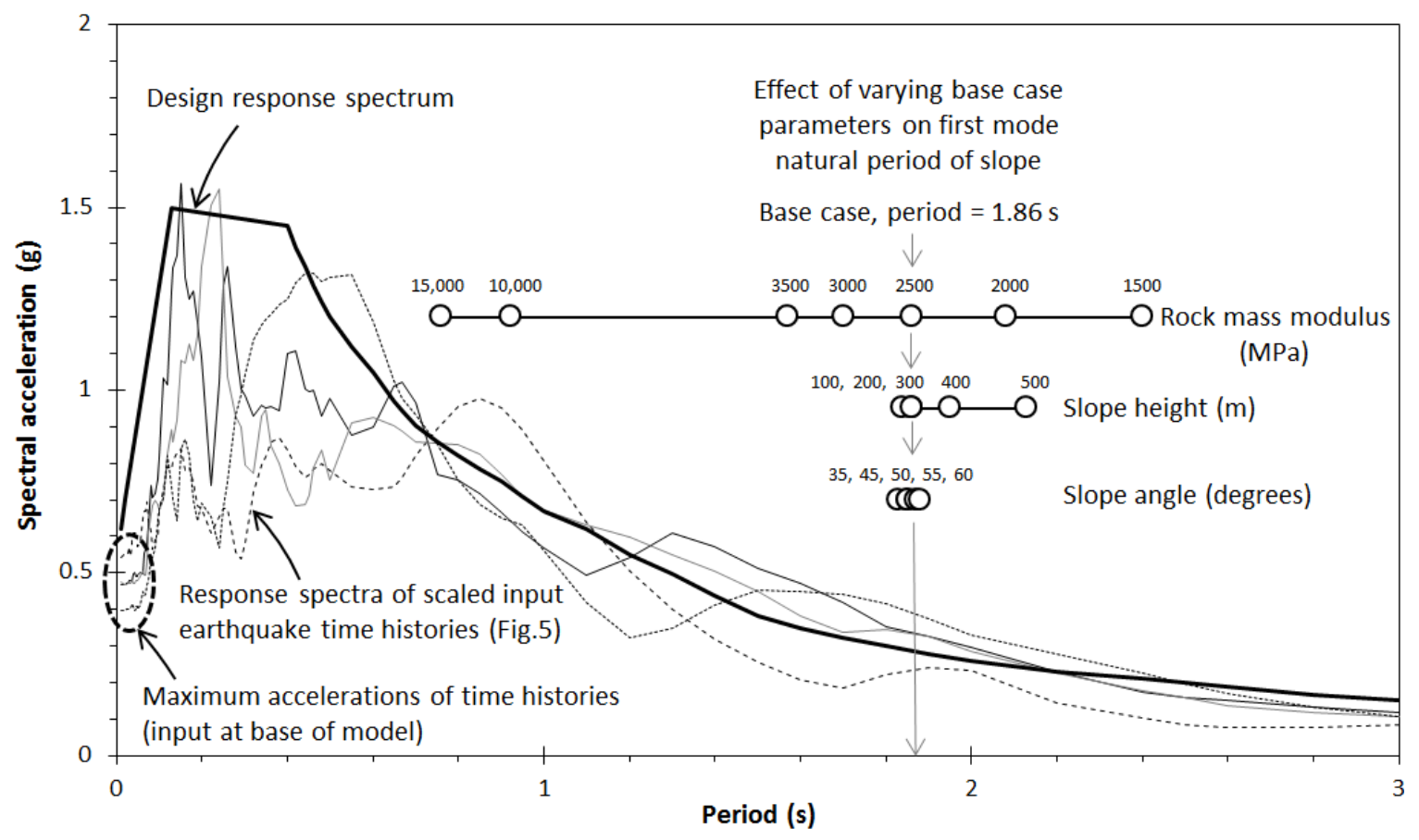

Figure 4 Relationship between typical response spectrum and pit slope modes

Estimating the natural period of the slope also allows earthquake acceleration time history records to be scaled appropriately. The authors usually use the method of NZS1170.5 (Standards New Zealand, 2004) to scale earthquake records for use in analysis. After selection of an appropriate suite of earthquake records, this methodology involves two key steps:

1. Scaling each individual record to minimise the difference between the record response spectrum and the design response spectrum, in a least mean squares sense, over the range of 40 to $130 \%$ of the first mode period of the slope.

2. Ensuring that, over this period range, at least one of the earthquake records in the suite exceeds the design spectrum.

An example of four earthquake records scaled to match the example design response design spectrum is shown in Figure 4, with the corresponding acceleration time histories shown in Figure 5. Note that the maximum accelerations of these records are the spectral accelerations at a period of zero seconds (i.e. the 
load that would be attracted if the slope were rigid), and that the records and design response spectrum in this example relate to the base of the parametric model (often they relate to the ground surface).

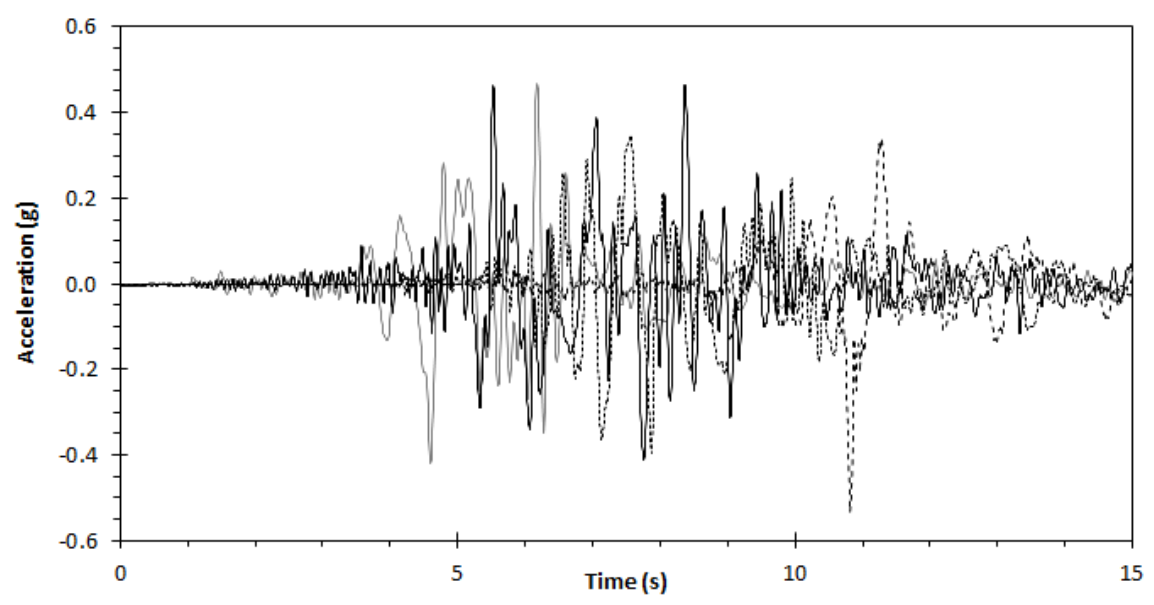

Figure 5 Earthquake acceleration time histories input to base of parametric model

\subsection{Implications for dynamic slope stability modelling}

The variation in first mode period compared to the response spectrum is significant (Figure 4); the design input spectral acceleration at the slope first mode period varies by about a factor of four across the analysed cases. This spectral acceleration indicates the magnitude of earthquake loading attracted by the slope. In this case, a stiffer slope (shorter natural period) would attract relatively higher spectral acceleration and therefore more intense earthquake loading.

Figure 6 demonstrates this by showing peak ground acceleration at the slope crest for the various parameter combinations. Accelerations were calculated by time history analysis, using the four earthquake records shown in Figure 5, with the ground motion input at the base of the model. As expected based on the results in Figure 4, as input spectral acceleration at the first natural period increases, peak crest acceleration increases, and vice versa. This is essentially a site response effect, demonstrating the way that motion is amplified or reduced by the slope. It follows that understanding dynamic site response is an integral part of earthquake engineering for large rock slopes.

Rock mass modulus and slope height have a significant effect on the crest acceleration. As suggested by Figure 4, the slope angles considered have almost no effect on slope period or crest acceleration. This indicates that topographical amplification (caused by the excavation of the pit slope) is not large.

\subsection{Implications for limit equilibrium slope stability modelling}

The results above show that peak ground acceleration of the bedrock input motion (spectral acceleration at zero period) is not a very important parameter in dynamic analysis of pit slopes. Spectral accelerations at other periods are shown to be more important, and comparisons can be drawn with dynamic analysis of structures. The implication of this is that the only earthquake loading parameter in limit equilibrium analysis (acceleration coefficient) is actually one of the least important in dynamic modelling. Combined with the observation that topographical amplification is small, makes it tricky to develop generic guidance for selecting a peak crest acceleration for limit equilibrium analysis.

This is demonstrated in Figure 7, which is prepared from the same time history analysis results as Figure 6 , but unlike Figure 6 it does not show any significant trends. From the results, the peak ground accelerations that occurred at any time during each earthquake were obtained at the crest of the slope, and at a point halfway between the slope crest and the far edge of the model (representing 'flat ground' response). Note these peak accelerations occurred at essentially the same instant in time. 

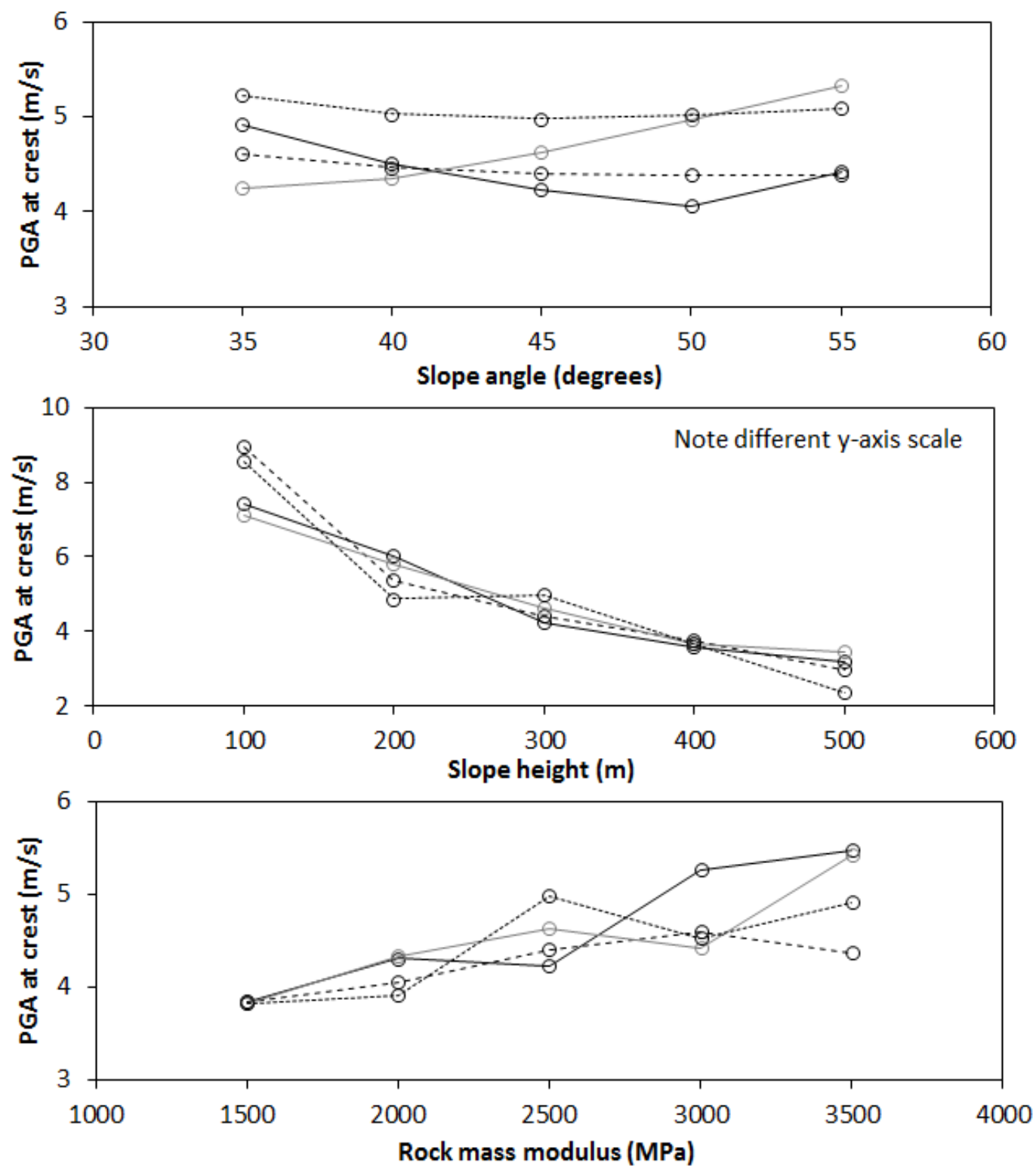

Figure 6 Peak crest acceleration compared to slope characteristics

The ratio of $P G A_{\text {crest }}$ to $P G A_{\text {flat ground }}$ is plotted, representing the topographical amplification effect. The results are variable and no trends are observed. However, the minimum ratio is approximately 0.7 and the maximum ratio is approximately 1.2, which is the maximum amplification factor recommended for limit equilibrium screening analysis in Section 3.3.4. Where the ratio is less than unity, this may be because the flat ground has a shorter natural period than the slope and therefore attracts a higher spectral acceleration. 

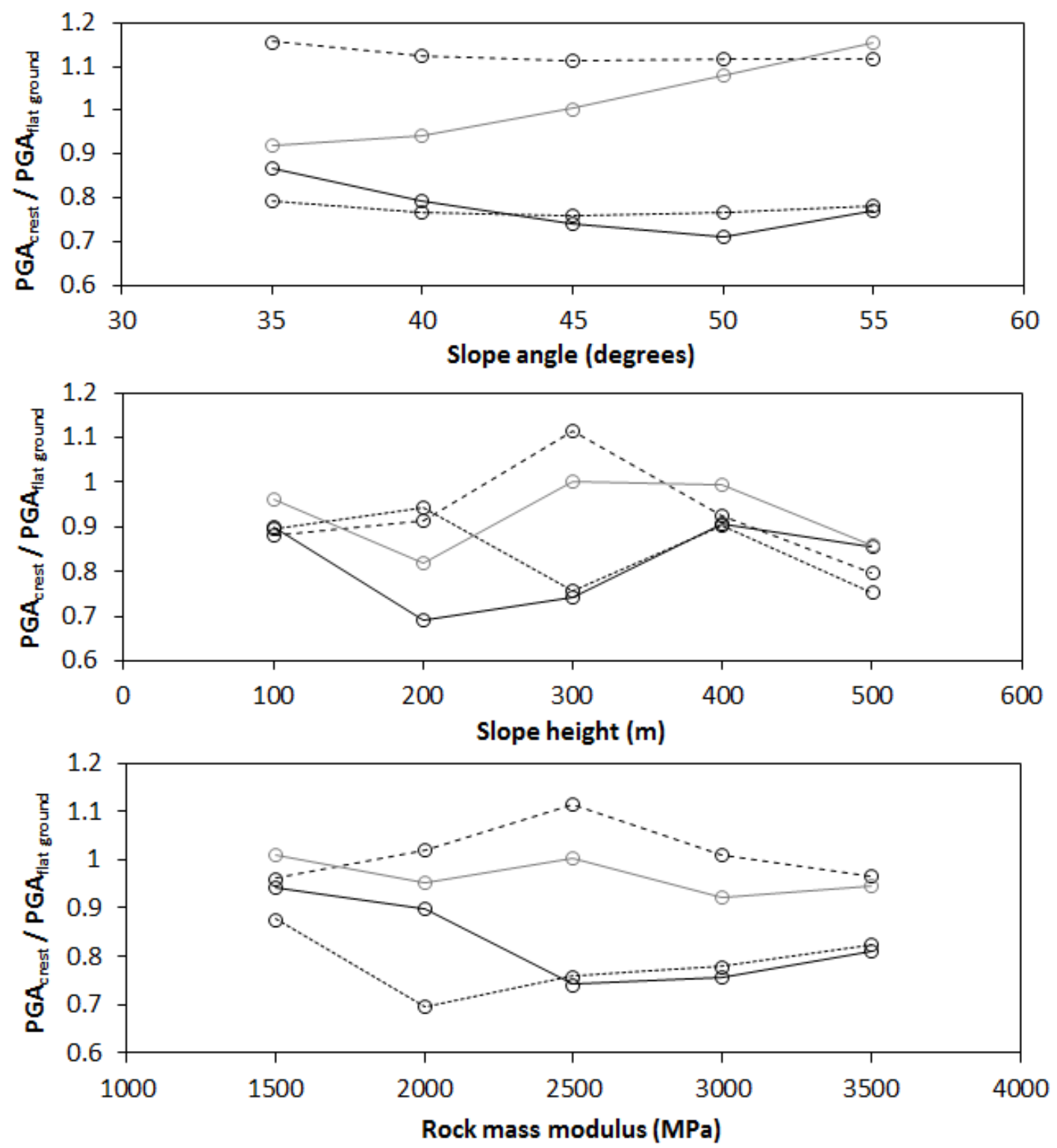

Figure 7 Peak crest acceleration normalised by peak flat ground acceleration

\section{$7 \quad$ Example of assessment of slope stability and deformation}

\subsection{Geotechnical and analytical model}

This example presents a brief summary of dynamic analysis of a $300 \mathrm{~m}$ high pit slope comprising medium and high strength rock mass, overlain by $50 \mathrm{~m}$ depth of very weak rock mass and sedimentary soils. It demonstrates compatibility between various types of analysis. The geotechnical model is summarised in Figure 8 , and material parameters are summarised in Table 3. Pore pressures were assumed to be $3 / 4$ of hydrostatic pressures calculated with the groundwater table at the surface. The modulus values correspond to the best-guess small strain rock mass modulus.

The analysis was undertaken using the Abaqus software (Simulia, 2012). The model was subjected to a very high earthquake excitation. Modal analysis (frequency domain) and time domain analysis using earthquake records were undertaken. The time histories used are those shown in Figure 5. 


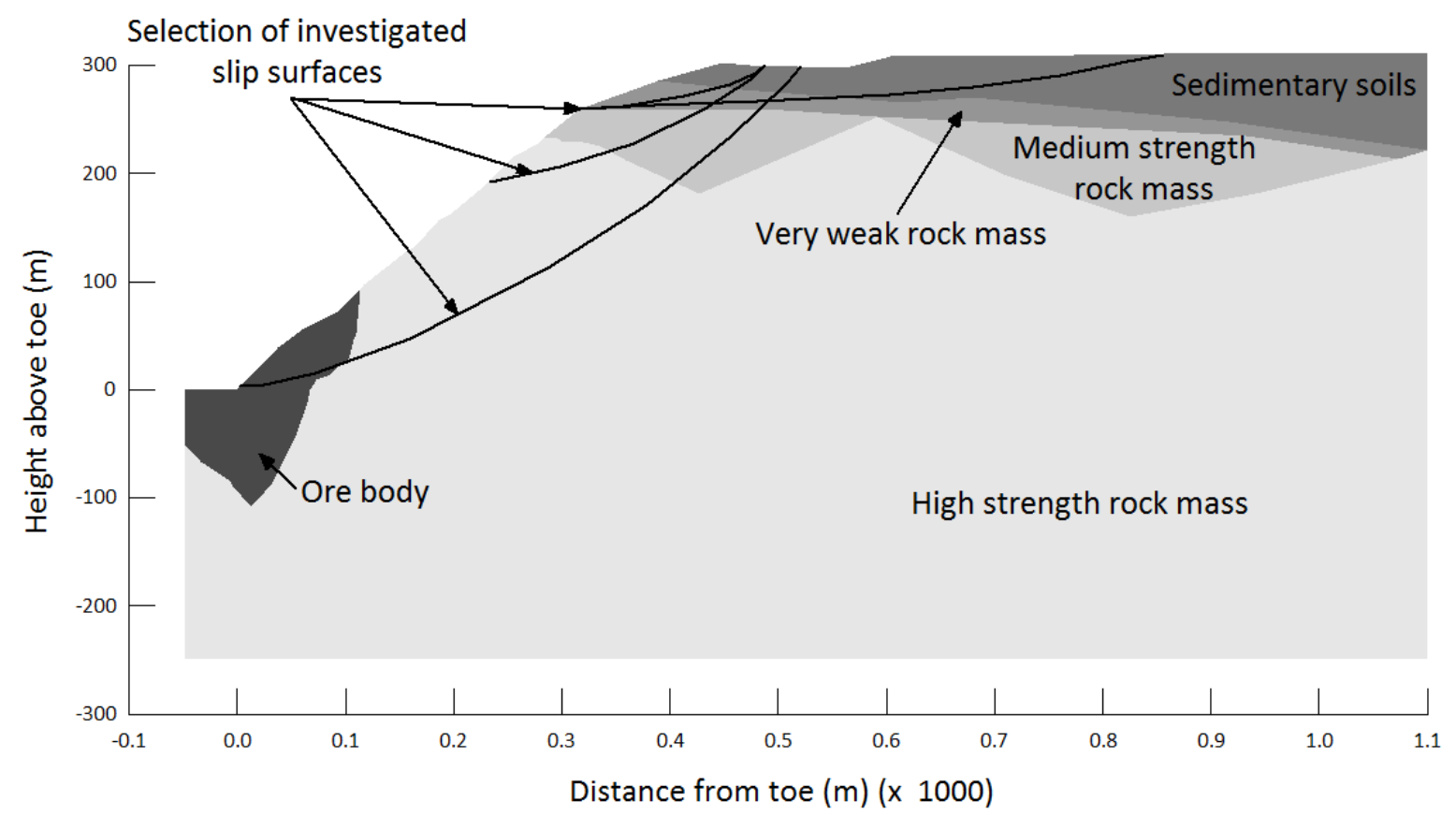

Figure 8 Geotechnical model for detailed study

Table 3 Parameters adopted for detailed study

\begin{tabular}{|c|c|c|c|c|c|c|c|}
\hline Material & $\begin{array}{c}\text { Unit } \\
\text { Weight } \\
\left(\mathrm{kN} / \mathrm{m}^{3}\right)\end{array}$ & $\begin{array}{c}\mathbf{c}^{\prime} \\
\text { (Equivalent) } \\
(\mathrm{kPa})\end{array}$ & $\begin{array}{c}\text { phi' } \\
\text { (Equivalent) } \\
\left(^{\circ}\right)\end{array}$ & $\begin{array}{c}\text { G } \\
\text { (MPa) }\end{array}$ & $\begin{array}{c}v_{s} \\
(\mathrm{~m} / \mathrm{s})\end{array}$ & $\begin{array}{c}v \\
\text { (Poisson's } \\
\text { ratio) }\end{array}$ & $\begin{array}{c}\text { Damping } \\
\text { (\%) }\end{array}$ \\
\hline $\begin{array}{l}\text { High strength } \\
\text { rock mass }\end{array}$ & 25 & 1,500 & 35 & 2,500 & 1,000 & 0.35 & 2 \\
\hline Orebody & 25 & 500 & 20 & 2,500 & 1,000 & 0.3 & 2 \\
\hline $\begin{array}{l}\text { Medium } \\
\text { strength rock } \\
\text { mass }\end{array}$ & 20 & 300 & 30 & 1,000 & 700 & 0.4 & 2 \\
\hline $\begin{array}{l}\text { Very weak rock } \\
\text { mass }\end{array}$ & 20 & 20 & 25 & 200 & 300 & 0.25 & 2 \\
\hline $\begin{array}{l}\text { Sedimentary } \\
\text { soils }\end{array}$ & 18 & 5 & 30 & 300 & 0.3 & 400 & 2 \\
\hline
\end{tabular}

\subsection{Results}

\subsubsection{General}

Results of modal analysis were examined to understand the dynamic response of the slope. Time history analysis results were interrogated to assess stresses, strains and yielding during the earthquake, and permanent displacements that had accumulated at the end of the earthquake due to yielding. Figure 9 summarises the results. 

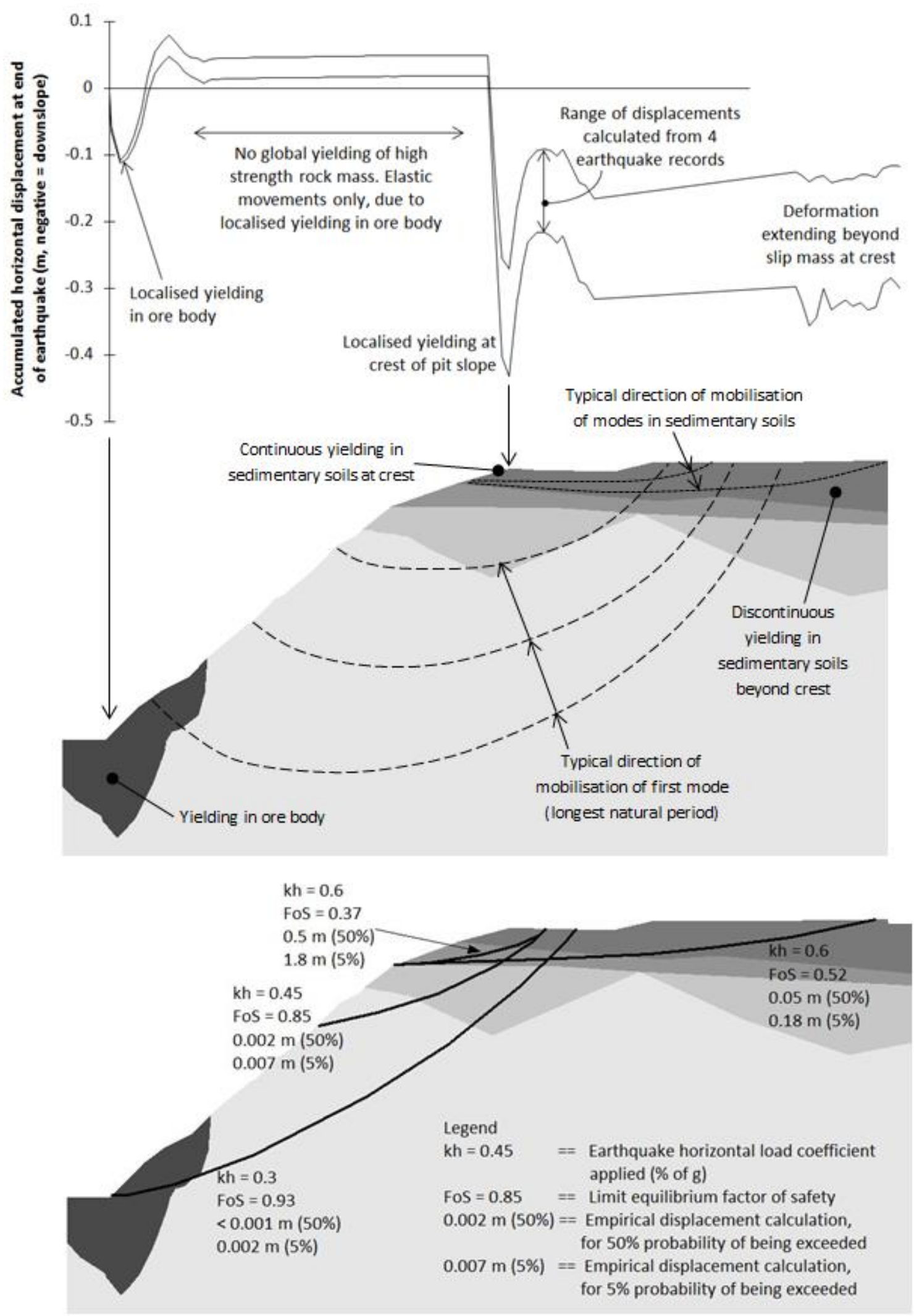

Figure 9 Summary of results from detailed study; top - horizontal displacement calculated in dynamic time domain numerical modelling; middle - pit slope modal shapes and natural periods from modal analysis, and areas of yielding from time domain analysis; bottom - Factor of Safety calculated in limit equilibrium analysis, estimated kh values used for analysis, and displacements calculated using empirical approach 


\subsubsection{Slope period and mode shapes}

Modal analysis shows that there are many modes within the overburden at the top of the pit slope (within the very weak rock mass and soils), and that these modes occur across a wide range of periods, including the periods of highest spectral acceleration in the earthquake response spectra. Therefore it is expected that these upper portions would attract a significant amount of earthquake energy. The longest period mode for lateral mobilisation of overburden is 1.5 seconds. In addition most modes within the overburden involve mobilisation of significant volumes of material, extending a significant distance back from the crest.

Modes encompassing the entire pit slope typically involve much lower relative displacements and occur at more discrete periods than modes within the overburden. Therefore the energy imparted on global slope failure mechanisms is expected to be less than for mechanisms within the overburden. The first mode (longest natural period) of entire slope is approximately 1.9 seconds. This is within the range of results from the parametric analysis in the above section.

\subsubsection{Global deformations (entire slope)}

During the time history analysis a continuous zone of yield from toe to crest is not developed for any of the earthquake records. Some localised yielding occurs in the relatively weaker orebody at the toe of the slope. The overall pit slope is therefore not expected to be subject to slope failure (a zone of continuous yield) or large displacements. Some small permanent displacement is modelled, this is a result of the hard rock slope above the orebody displacing elastically (without yielding) towards the zone of yielding at the toe.

\subsubsection{Deformations in upper slopes and pit crest}

The upper portion of the pit slope is within very weak rocks and soil. When subjected to the earthquake extensive yielding is expected at the crest at several instances during the earthquake. However, this 'failure' does not extend back that far and the depth is limited to the depth of soils and very weak rock mass.

Deformations in the order of half a metre are expected, even assuming no softening, see Figure 9.

\subsubsection{Deformations beyond pit crest}

Other mechanisms are possible in the overburden that are not directly related to slope instability, such as liquefaction and lateral spreading, strain softening, and settlement and squeezing; such effects could occur regardless of the existence of the pit slope.

In this model, occasional localised yielding in an elongated zone extending several hundred metres back from the pit crest is observed in the time history analysis, but no well-defined 'slope movements' or continuous yield zone develops that extends any significant distance back from the crest.

Although this yielding is not directly related to slope movement, some permanent downslope displacements are expected to result from the yielding as the surficial material is allowed to 'follow' the displaced crest downslope; the modelling suggests that they are typically limited to approximately $0.3 \mathrm{~m}$ at distances greater than $30 \mathrm{~m}$ back from the crest (the approximate distance to which the crest slope failure mechanism extends).

\subsection{Comparison with simpler analysis}

A comparison is made with the results of pseudo-static limit equilibrium analysis (calculating a Factor of Safety for a 'flat ground' PGA of $0.6 \mathrm{~g}$ (the PGA of the example input design spectrum, see Figure 4) and estimating $k_{h}$ based on the guidelines in Section 3.3.4). Displacements were assessed empirically using the method of Ambraseys and Menu (1988), for displacements of both 50 and 5\% probability of being exceeded. The full results of these analyses are not presented due to space restrictions. The results and estimating $k_{h}$ values used in the analysis are summarised in Figure 9. 
Global slope displacements from the dynamic numerical modelling are compatible with the limit equilibrium results which have an overall global Factor of Safety slightly less than unity for the design earthquake. Based on the dynamic analysis results, the limit equilibrium results are interpreted as Factor of Safety significantly less than unity in the weaker orebody but greater than or approximately equal to unity for the remainder of the hard rock slope, so although calculated Factor of Safety is slightly less than unity, there is no global slope failure expected.

Displacements at the slope crest from the numerical analysis are similar to those calculated empirically based on the limit equilibrium analysis corresponding to a $50 \%$ probability of being exceeded.

This extent of displacements back from the slope crest in numerical modelling is similar to that which might be indicated by the limit equilibrium and empirical displacement analyses, which had Factor of Safety less than unity for pre-specified elongated potential failure surfaces extending several hundred metres back from the crest. Displacements beyond the crest from dynamic modelling are similar to those calculated empirically based on the limit equilibrium analysis corresponding to a $5 \%$ probability of being exceeded.

\section{Conclusions}

There is little precedent for methods of assessing the earthquake stability of large open pit rock slopes. The authors have considered a range of different analytical approaches in an attempt to account for the unique characteristics of these slopes. It is concluded that although slope response and stability is not fully understood until a range of different analyses are completed, reasonable compatibility between different types of analyses can be obtained.

Both time domain and frequency domain dynamic analyses are useful for understanding aspects of dynamic slope behaviour. These analyses usually show that the slope response is highly sensitive to the interaction between the earthquake characteristics and the slope characteristics. The first mode (longest natural period) of a slope is sensitive to rock mass modulus and slope height; analogies can be made with one-dimensional site response analysis. It is evident that spectral accelerations, especially spectral acceleration at the first mode period, affect the seismic loading experienced by a slope more so than peak ground acceleration. It follows that understanding site response is an integral part of earthquake engineering for large rock slopes, and that input motions for dynamic analysis must be carefully selected and scaled.

Limit equilibrium analysis is considered to be suitable for screening studies and adequate for most applications, but its limitations prevent a detailed understanding of the dynamic slope behaviour. The selection of an earthquake load coefficient for limit equilibrium analysis should be based on the principles of slope dynamics, to achieve appropriate results.

\section{References}

Ambraseys, N.N. and Menu, J.M. (1988) Earthquake-induced ground displacements, Earthquake Engineering and Structural Dynamics, International Association for Earthquake Engineering, Vol. 16(7), pp. 985-1006.

Ashford, S.A., Sitar, N., Lysmer, J. and Deng, N. (1997) Topographic effects on the seismic response of steep slopes, Bulletin of the Seismological Society of America, Vol. 87(3), pp. 701-709.

Bouchon, M. (1973) Effects of topography on surface motion, Bulletin of the Seismological Society of America, Vol. 63(2), pp. 615-632.

Geo-Slope (2007) Geostudio 2007 Quake/W software, http://www.geo-slope.com/products/quakew.aspx.

Itasca (2007) FLAC software v6, http://www.itascacg.com/flac/.

Makdisi, F.I. and Seed, H.B. (1978) Simplified procedure for estimating dam and embankment earthquake-induced deformations, ASCE Journal of the Geotechnical Engineering Division, Vol. 104(GT7), pp. 849-867.

Read, J. and Stacey, P. (2009) Guidelines for open pit slope design, CSIRO Publishing, Victoria, Australia.

Simulia (2012) Abaqus software v6.12, http://www.3ds.com/products-services/simulia/portfolio/abaqus/latest-release/.

Standards New Zealand (2004) NZS1170.5, Structural design actions, Part 5: Earthquake actions - New Zealand.

Toh, J.C.W. (2010) Seismic analysis for open pit mines, Australian Geomechanics Society, Sydney Chapter Symposium, 13 October 2010, Sydney, Australia. 
